IMAGINATION, COGNITION AND PERSONALITY, Vol. 26(1-2) 65-86, 2006-2007

\title{
CREATIVE TYPES AND PERSONALITY
}

\author{
ZORANA IVCEVIC
}

JOHN D. MAYER

University of New Hampshire

\begin{abstract}
The present study aimed to identify types of creative activities and to examine which personality traits differentiate these behavioral types. Participants reported their activities concerning creative life-style, artistic creativity, and intellectual achievement. Also, they completed measures of personality traits concerning whole personality, emotions and motivation, cognition, social expression, and self-regulation. Five types of individuals were identified based on the profiles of creative activities in which they participated: conventional, everyday creative individuals, artists, scholars, and renaissance individuals. One set of traits distinguished conventional from other groups (traits general to different kinds of creativity) and another set of traits distinguished scholars from other groups (traits specific to one kind of creativity). Implications for the study of creative personality and development of creativity are discussed.
\end{abstract}

Creativity was discussed from the outset of modern personality psychology: by such grand theorists of personality as Freud [1] and Maslow [2], as well as by such influential founders of trait psychology as Eysenck [3] and Guilford [4]. It remains a concern of many contemporary researchers as well [5-7]. Different kinds of creativity can be distinguished and personality similarities and differences among them can be examined [5].

Creativity is usually studied in formal domains of work, such as the arts, and the emphasis is put on understanding personal and social attributes related to creativity in a specific domain $[5,8]$. At least three broad kinds of creativity are 
recognized both by scholars and lay people [9]: artistic and scientific creativity refer to commitment and achievement in their respective domains, and everyday creativity concerns self-expressiveness and originality in daily activities and relationships that do not carry social recognition and do not necessarily require technical skill. Similarly, Kaufman and Baer [10] found three dimensions in self-reports of creativity. The dimension described by creativity in communication and interpersonal relationships is similar to everyday creativity; the dimension described primarily by crafts and arts can be labeled artistic creativity; and the dimension described by math and science concerns scientific or intellectual creativity. Research shows that relatively distinct domains of creativity can be defined theoretically and identified empirically, but also that there are some commonalities among creativity in different domains $[5,10]$.

In this article, we will examine how people express creativity in their everyday behavior. We will address the issue of domain specificity and generality in creativity by adopting a typological approach. We will ask whether there are distinct creative types and whether it is possible to identify both relatively general types (i.e., people who show creativity in multiple domains) and domain-specific types. Can these types be distinguished by different sets of personality traits? To address these questions, we first identify creative types as groups of individuals with different profiles of creative behavior in the domains of art, intellectual achievement, and everyday life. Then, we select personality traits from different functional areas of personality and analyze them in relation to the creative types.

\section{WHAT IS CREATIVITY?}

According to one prominent definition, creativity refers to a product or behavior that satisfies criteria of originality and appropriateness [11]. This definition suggests a distinction between creative potential (psychological attributes that enable originality) and expressed creativity (or creative behavior). Creativity can be expressed in many formal domains of work, such as the arts, sciences, and business $[12,13]$. Creativity in formal domains of work requires specific abilities and learning, and is sanctioned by an organized system of judges (e.g., art critics or journal reviewers). However, creativity also exists in everyday life; it permeates daily life in areas of self-expression and presentation, managing personal relationships, practical artistry, and culture participation. An original and appropriate product could be a painting exhibited in an art gallery, but it could also be a device that helps one's disabled child with locomotion [14].

When multiple areas of artistic and intellectual creativity are assessed by behavior checklists, more than one dimension of creativity emerges. Guastello and Shissler [15] identified two correlated dimensions of creativity, one pertaining to artistic and one pertaining to intellectual creativity. When everyday creativity is also measured, it becomes possible to distinguish three dimensions, including creative life-style, performing arts, and intellectual achievement [16]. 
Creative life-style refers to originality in self-expression (e.g., designing one's own jewelry), interpersonal behavior (e.g., creating a scrapbook of memories for a friend), and culture participation (e.g., organizing a poetry recital), and also includes the creative leisure activities of writing and visual arts (e.g., writing poetry, completing paintings). The originality and appropriateness of creative life-style behaviors is defined largely in relation to its subjective meaning for the creator or a relatively small group of significant others in his or her life. For example, a gift for a friend could be creative (i.e., original and appropriate) in the context of that specific relationship. In contrast, creativity in the performing arts and intellectual achievement is rare; these forms of creativity require specific learning, and indicate a certain level of socially recognized accomplishment (e.g., performing music in public or acting on stage).

Another way to examine creative behavior asks whether it is possible to identify groups of individuals with distinct patterns of behavior. If it were possible to define such groups, we could talk about creative types. Many people may have profiles that peak on one kind of creativity, but others might exhibit multiple creativities. Indeed, biographical studies of eminent creators show that many are involved in multiple creative endeavors. Root-Bernstein and colleagues [17-19] examined activities outside of an individual's primary area of work for Nobelprize winners in literature and chemistry. Each sample showed evidence of involvement in multiple creative endeavors. More than one-third of Nobel laureates in literature were involved in at least one other artistic area (visual arts, music, drama, or dance) and one-fifth had some involvement in science or engineering (in their education, as a temporary career, or in self-study/avocation). These numbers might have been even higher, as there was no information available on the non-writing activities of many individuals. Similarly, many Nobelprize recipients in chemistry were active in the arts, crafts, and writing, and had greater involvement in these activities than their less eminent peers.

\section{CREATIVITY AND PERSONALITY}

There is a general agreement that creativity is a syndrome that requires multiple resources within a person [20-22]. Similarly, personality can be defined as a system of psychological attributes that describe how one feels, thinks, interacts with the social world, and regulates behavior [23-24].

There are at least two broad approaches to identifying and organizing personality attributes. The first approach stems from the lexical hypothesis and postulates that the most important personality traits can be identified in the language [25]. Research with the lexical hypothesis indicates that such trait terms can be organized into five broad dimensions: extraversion, agreeableness, conscientiousness, neuroticism, and openness to experience (i.e., the Big Five). The second approach employs a functional hypothesis $[24,26]$. One version of the functional hypothesis states that personality can be divided into partially distinct 
areas, each performing a different set of operations, and that behavior results from a collective action of these areas. Personality can be divided in five broad areas: a) emotions and motivation direct behavior and include traits of motivational orientations, emotional valence, and intensity; b) cognition processes information and includes mental abilities, concepts of the self, others, and the world; c) social expression refers to approaches to social interactions and includes social skills and identification with social roles; d) self-regulation supervises the other areas of personality and manages their operation for desired outcomes; and e) whole personality refers to large traits that bridge multiple functions $[24,26]$.

These two approaches can be viewed as compatible and mutually supportive, in that the major trait dimensions identified based on the lexical hypothesis tend to be rather holistic in relation to personality functions. In this research we use both approaches. We select one broad trait that represents the whole personality and that is based on the Big Five model (i.e., openness to experience) and we also select narrower traits that represent functional areas of personality (e.g., trait of nonconformity in the area of social expression).

\section{Whole Personality}

In recent decades, the Big Five has become a dominant model for describing broad personality traits $[25,27]$. The Big Five trait of openness to experience has been theoretically and empirically defined as a general disposition for creativity [7]. On average, artists and scientists are more open to experience than non-artists and non-scientists [5], and openness is related to criteria such as the number of creative activities reported by college students [6], playing musical instruments [28], and self-reported involvement in visual, literary, performing, and domestic arts [29].

\section{Emotions and Motivation}

Creativity is also related to narrower traits in the areas of emotions and motivation, cognition, social expression, and self-regulation. Emotions and motivation direct behavior into activities that offer opportunities for creation, and may serve as a source of creative ideas [20]. For example, people who are intrinsically motivated engage in an activity because of pleasure in creating or enjoyment in an opportunity for self-expression [20]. They spend more hours of work per week doing art, and are rated more highly as to their artistic potential by their instructors [30]. Intrinsic motivation is also related to sustained activity in biographical studies of eminent creators in diverse domains [12]. ${ }^{1}$ Another trait related to creativity is trait hypomania; it is correlated both with measures of

\footnotetext{
${ }^{1}$ See also research by Eisenberger and colleagues [31, 32] for a demonstration of circumstances under which extrinsic motivation can enhance creativity.
} 
creativity potential (e.g., self-perceived creativity) and creative behavior (e.g., involvement in creative activities [33-35]). Hypomanic moods increase awareness and enhance the breadth, fluency, and flexibility of thinking [36].

\section{Cognition}

Cognitive abilities enable the generation of creative ideas. Most centrally, divergent thinking abilities are involved in the production of ideas, whereas evaluation abilities contribute to appropriateness of a generated product. Divergent thinkers are able to generate a large number of responses that satisfy a certain criterion (fluency) and produce responses that depart from the ordinary and obvious (originality) [4]. In concurrent validity studies, divergent thinking predicted creativity ratings by knowledgeable others and self-reports of creative activity $[6,15,37]$. In longitudinal studies, divergent thinking in elementary school predicted creative achievement and career aspirations even 22 years later [38]. Evaluation takes place throughout the process of creation. Adequate judging of uniqueness of ideas significantly correlates with their originality $[39,40]$. Furthermore, both schizophrenic patients and artists produce unusual responses on a word association task, but only creative artists give appropriate (i.e., nonbizarre) responses and are able to evaluate their uncommonness [41]

\section{Social Expression}

Enactment of certain social roles has often been equated with creativity. For instance, on the Occupational Creativity Scales individuals in investigative and artistic occupations (e.g., professors and writers) are rated the highest on creativity and are then differentiated depending on the level of public recognition in their professions [42]. Similarly, self-identifications with artistic and investigative roles are related to faculty ratings of creativity in psychology graduate students [43]. Creativity is also related to a number of social traits, such as non-conformity, and individualism [44]. For example, women described by Q-sort items "tends to be rebellious and non-conforming" and "judges in unconventional ways" at ages 21 and 43 were likely to have high occupational creativity at age 52 [42]. Similarly, successful artists and scientists score high on psychoticism, a broad trait described by adjective markers such as nonconforming and uninhibited $[45,46]$.

\section{Self-Regulation}

The function of self-regulation is to oversee and balance the process of creation and sustain conscious effort in creative activity. One mechanism of self-regulation employed by creators is their willingness to take moderate risks [22]. An individual can choose a familiar and relatively commonplace option or a more unconventional route leading to greater originality. Risk-taking is related to originality on tests of creative ability [47, 48], involvement and enjoyment in 
drawing and writing, creativity on a laboratory drawing task, and unconventionality in writing [49]. Creativity also requires discipline, hard work, and persistence. While persistence is not significantly related to creative performance on short laboratory tasks [49], it predicts real life creativity that requires long periods of sustained activity, often times in face of substantial obstacles. For example, Wilson [50] found that poets persisted in writing even in times of prolonged economic deprivation and long periods without critical acceptance for their work.

All studies cited in this short review concerned covariation of dimensions of creativity and personality across people. In the past, this research strategy has proved very useful in learning about creativity and personality, especially in the arts and sciences. An alternative approach to the study of creativity and personality would analyze patterns of creative activities in different groups of people and examine personality differences among these groups [51]. The present study will adopt this latter approach.

\section{METHOD}

\section{Participants}

The participants were 488 students in lower level psychology courses at the University of New Hampshire who received course credit as compensation. After handling incomplete and invalid data, the final sample consisted of 416 subjects (115 males and 300 females; 1 participant did not indicate gender). Most of the sample was of traditional college age (97.8\% participants between 17 and 22 years) and $87 \%$ were in the first or second year in college. Most participants were Caucasian (95\%) and from middle class families, with $71.6 \%$ reporting household incomes above $\$ 60,000$. A high percentage of participants were from highly educated families; $47.5 \%$ of the mothers and $52 \%$ of the fathers held bachelors degree or higher.

\section{Measures}

\section{Creativity Questionnaire}

The questionnaire consisted of 244 items which asked participants to report on their creative behaviors and group memberships relevant to several areas of creative expression [16]. Creative behaviors concerned interactions with other people (e.g., surprising a friend with a gift), interactions with settings or situations (e.g., read one's own piece in a recital), and interactions with objects or materials (e.g., painting a piece of furniture). Also, the questionnaire contained items about memberships in organized groups that promote creativity in high school and college (e.g., dance teams or literary magazines). Item content was based on open-ended surveys of college students, review of existing inventories of creative 
behavior, and behavioral criteria for creativity used in previous research [29, $30,52,53]$.

The questionnaire was scored for three dimensions of creative behavior identified in previous research: creative life-style, performing arts, and intellectual achievement. Creative life-style items referred to crafts (e.g., making collages), culture refinement (e.g., having a conversation about art), sophisticated media use (e.g., researching a topic of interest on the Internet), self-expressive creativity (e.g., designing a tattoo), interpersonal creativity (e.g., surprising a friend with a gift), and leisure time activities in visual arts and writing (e.g., writing poems). Performing arts concerned music (e.g., playing music in public), dance (e.g., dancing in a ballet), and theater (e.g., acting on stage). Intellectual achievement referred to science (e.g., presenting research at a conference), technology (e.g., writing software), and academic orientation (e.g., publishing a paper in a journal for undergraduate research).

\section{Selecting Personality Predictors}

Personality was defined as including traits of whole personality, as well as traits from four major structural areas: a) emotions and motivation; b) cognition; c) social expression; and d) self-regulation [24]. Personality predictors were selected to represent each of these five areas. Whole personality predictor was the Big Five trait of openness to experience and traits in four specific areas of personality functioning were selected based on two criteria. First, predictors were sampled to equally represent each of the four areas of personality (two traits per area). Second, all predictors had to be theoretically and empirically related to creativity. The measures are described below.

\section{Whole Personality}

Openness to experience was measured by the Big Five Inventory (BFI) [54]. Participants rated themselves on adjective or short trait descriptions (e.g., "ingenious, a deep thinker") using a 5-point scale $(\alpha=.79)$.

\section{Emotions and Motivation}

Intrinsic motivation was assessed by the Work Preference Inventory (WPI) [30]. The scale asked about enjoyment (e.g., "What matters most to me is to enjoy what I do") and challenge in work (e.g., "I want my work to provide me with opportunities for increasing my knowledge and skills"). Participants gave ratings on a 5-point scale $(\alpha=.76)$.

Trait hypomania was assessed by the Hypomanic Personality Scale [33]. Participants answered questions using a true-false format. Items assessed euphoric affect and energy level (e.g., "I am frequently so 'hyper' that my friends kiddingly ask me what drug I'm taking"), mood swings (e.g., "I seem to be a person whose 
mood goes up and down easily"), speed and fluency of thought (e.g., "Sometimes ideas and insights come to me so fast that I cannot express them all"), and high ambition and self-confidence (e.g., "I expect that someday I will succeed in several different professions"). The scale provided a total index of hypomanic personality $(\alpha=.84)$.

\section{Cognition}

Divergent thinking ability was assessed by the Instances subtest from the Wallach and Kogan [55] test battery. Participants were asked to think of as many items as they can in four categories (i.e., round things, square things, things that make noise, and things that move on wheels) and they were instructed to be creative in their responses. Divergent thinking was scored for frequency (i.e., total number of responses) and a total score was computed by summing $z$-scores for four test items $(\alpha=.78)$.

Evaluation ability was assessed by the multiple-choice version of the Symbol Equivalence Test [56]. The test assesses the ability to use analogical thinking in recognizing appropriate and original metaphors equivalent to a presented stimulus image. Ten symbolic images were presented, each followed by four pairs of alternative responses. For example, a stimulus image "a train going into a tunnel" was followed by two suggested symbolic equivalents "a needle being threaded" and "rabbit in hole." "A needle being threaded" is scored as a better alternative; both a train going into a tunnel and a needle being threaded enter a narrow opening and exit on the other side. The score on this test was the number of correctly evaluated symbolic equivalent images $(\alpha=.77)$.

\section{Social Expression}

Social nonconformity was assessed by the Impulsive Nonconformity Scale [57]. Participants answered questions using a true-false format. Items assessed disregard for social convention (e.g., "I break rules just for the hell of it"), impulsivity and lack of self-control (e.g., "I prefer being spontaneous rather than planning ahead"), and mild antisocial behavior (e.g., "During one period when I was a youngster, I engaged in petty thievery"). Since impulsivity is not considered to be a core predictor of creativity, only items pertaining to social nonconformity and mild antisocial behavior were scored $(\alpha=.80)$.

Role identification was computed as an individual's maximum rating for the roles of artist and scholar. A total score was computed for each role by averaging ratings across four different settings: in school, when they want to relax/in leisure time, with friends, and with family. Ratings were done on a 5-point scale. 


\section{Self-Regulation}

\section{Intellectual Curiosity and Persistence}

Items from the Persistence Scale [58] and the Cognitive Persistence Scale [59] were factor analyzed to identify one factor of persistence in problem solving tasks [60]. The factor-based scale was labeled intellectual curiosity and persistence and it referred to preference for new and complex material (e.g., "I prefer intellectual task to one that doesn't require much thought") and persistence in face of obstacles (e.g., "Even if I fail to solve a problem, I try again and again and hope that I will find the solution"). Participants responded using a 5-point rating scale $(\alpha=.73)$.

Risk-taking was measured by a scale of monetary risk from the Risk-Taking Personality Inventory [61]. Items asked about one's preference for ventures with great potential gains (e.g., "The higher the stakes, the more I would enjoy the bet") and willingness to pursue a line of work that could compromise one's security (e.g., "I would enjoy the challenge of a project that could mean either a promotion or loss of a job"). Participants responded using a 5-point rating scale $(\alpha=.75)$.

\section{Procedure}

Data were collected in two testing sessions in groups of 20-40 participants. Each session included measures of creativity and personality traits. In the first session, participants were informed about the general purpose of the study and then were presented an informed consent form. They then filled out half the scales; they completed the second group of scales during the second session. Debriefings were presented upon completion of the study. To ensure anonymity, all subjects received a code that was used to match responses from two assessment sessions; no identifying information was recorded with the test materials.

\section{RESULTS}

Scores on creative life-style, performing arts, and intellectual achievement scales were first used in a cluster analysis to identify groups of people with similar patterns of creativity (i.e., creative types). Then, differences among these types were described in relation to personality traits using discriminant function analysis.

\section{Clustering Creative Behavior}

Scores on creative life-style, performing arts, and intellectual achievement scales were cluster analyzed using Ward's clustering method. This procedure was chosen as a method that minimizes the variance within clusters and is one of the most accurate in validation studies with known cluster membership [62, 63]. The number of retained clusters was determined based on the change in fusion coefficients and meaningfulness. 
Creativity is statistically rare; thus, it was hypothesized that the largest cluster of people would be low on all dimensions of creativity. Additional clusters were expected to include individuals with peak scores on one dimension of creativity. Finally, the smallest cluster was hypothesized to include individuals with above average scores on all three dimensions of creativity. This cluster structure would support the findings of statistical infrequency of creativity, domain specificity in creativity for most individuals, and generality in creativity for a small number of people [64].

Five clusters of individuals were identified and interpreted as: the Conventional Person, the Everyday Creative Person, the Scholar, the Artist, and the Renaissance Person (see Figure 1). The Everyday Creative Person cluster was the largest $(N=160)$ and it was described by above average scores on creative life-style and below average scores on performing arts and intellectual achievement. The size of this cluster supports theoretical claims that creativity manifested in unique

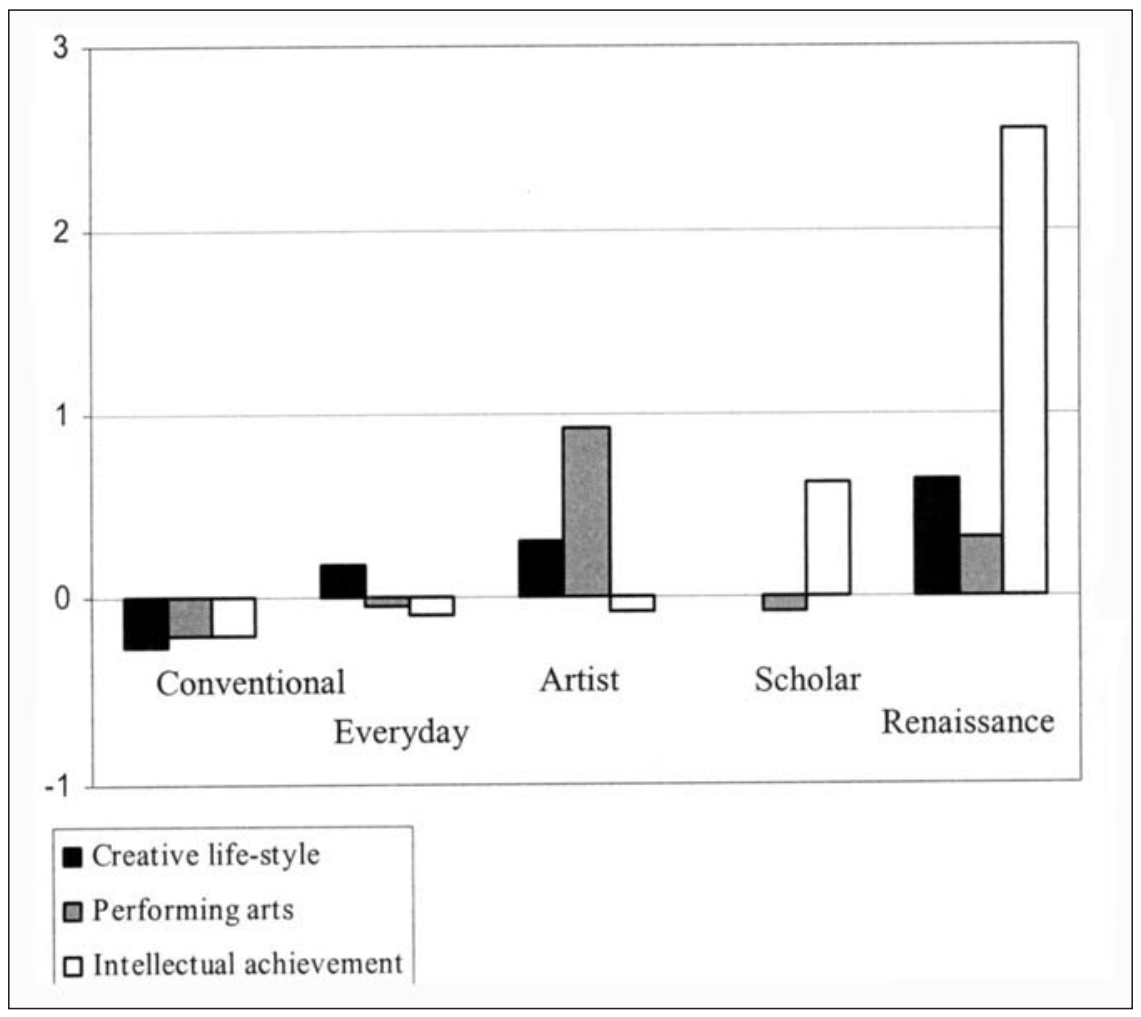

Figure 1. Mean scores on three dimensions of behavior for five clusters of creativity. 
self-expression is relatively common in the general population. The Conventional Person cluster was the second largest $(N=139)$, and included individuals with below average scores on all measures of creativity. This cluster shows that large groups of people are not willing to behave in unconventional ways, but rather resort to the familiar [22].

The next two clusters had peak scores on one dimension of creativity. The third cluster described the Scholar; this group had highest scores on intellectual achievement, average scores on creative life-style, and below average scores on performing arts $(N=59)$. The fourth cluster described the Artist; it had highest scores on performing arts, above average scores on creative life-style, and was below average on intellectual achievement $(N=52)$. The final cluster, labeled the Renaissance Person, was the smallest $(N=6)$; as hypothesized, only a small number of individuals showed above average scores on all dimensions of creativity, with highest scores on intellectual achievement.

After initial cluster identification, replicability of identified clusters was tested using randomly divided halves of the sample for cross-validation $[65,66]$. The first four clusters were closely replicated in two validation samples (see Figure 2). The fifth cluster had only two individuals in each validation sample. In both samples the highest score describing the fifth cluster was intellectual achievement, while there was a pronounced difference on the two other dimensions. However, the small number of individuals makes any differences likely to be due to sample idiosyncrasies.

\section{Personality Profiles Predictive of Cluster Membership}

A discriminant function analysis was performed to identify personality traits that predict membership in groups identified in the cluster analysis. The Renaissance Person cluster was dropped from analysis because of its small size and the discriminant analysis was performed on the remaining four groups. Two discriminant functions were identified, with a combined $\chi^{2}(27)=114.92, p<.001$. Both functions were individually significant; the second discriminant function was significant at a high level of confidence, $\chi^{2}(16)=42.21, p<.001$. Canonical correlations were .41 and .29 for discriminant functions one and two respectively. Two functions pooled together explained $25 \%$ of the variance in the differences between clusters (Wilks' $\lambda=.75$ ), and the second discriminant function alone explained $10 \%$ of the variance (Wilks' $\lambda=.90$ ).

Table 1 shows correlations between personality predictors and standardized canonical functions (loadings). Applying the criterion of .30 for the loadings in interpreting discriminant functions, the first function was described by creative role, openness to experience, intellectual curiosity and persistence, and trait hypomania. As can be seen in Figure 3, this group of traits primarily distinguished the Conventional Person cluster from the Artist cluster, with the Everyday 


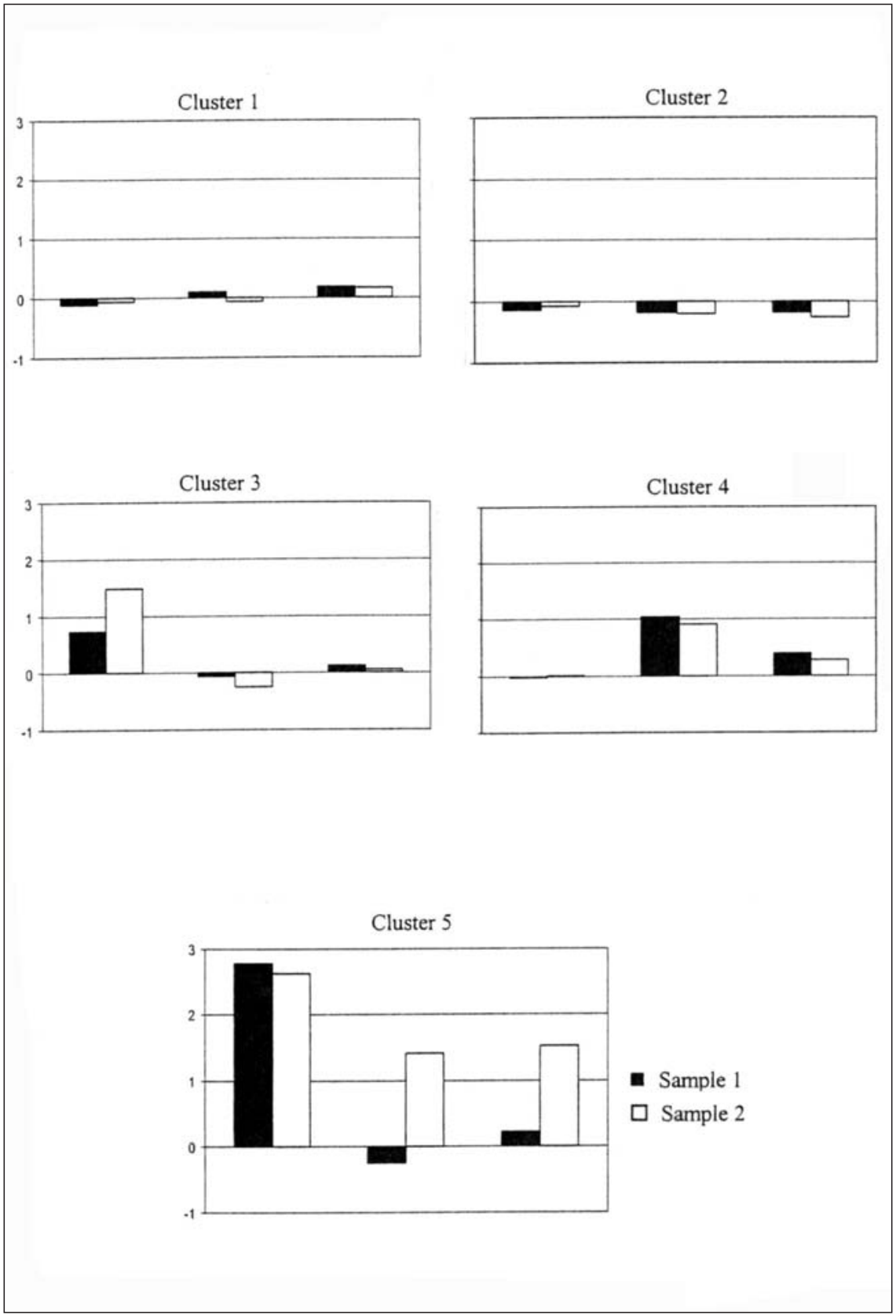

Figure 2. Replicability of a five-cluster solution for dimensions of creative behavior. 
Table 1. Personality Traits Distinguishing Creative Types: Discriminant Function Analysis (Structure Matrix)

\begin{tabular}{lll}
\hline & I & II \\
\hline Creative role & .72 & \\
Openness to experience & .70 & \\
Intellectual curiosity and persistence & .52 & \\
Trait hypomania & .48 & \\
Intrinsic motivation & .43 & \\
Monetary risk & & .68 \\
Divergent thinking & & .52 \\
Nonconformity & & .32 \\
Evaluation & & \\
\hline
\end{tabular}

Note: Only loadings greater than \pm .30 are shown.

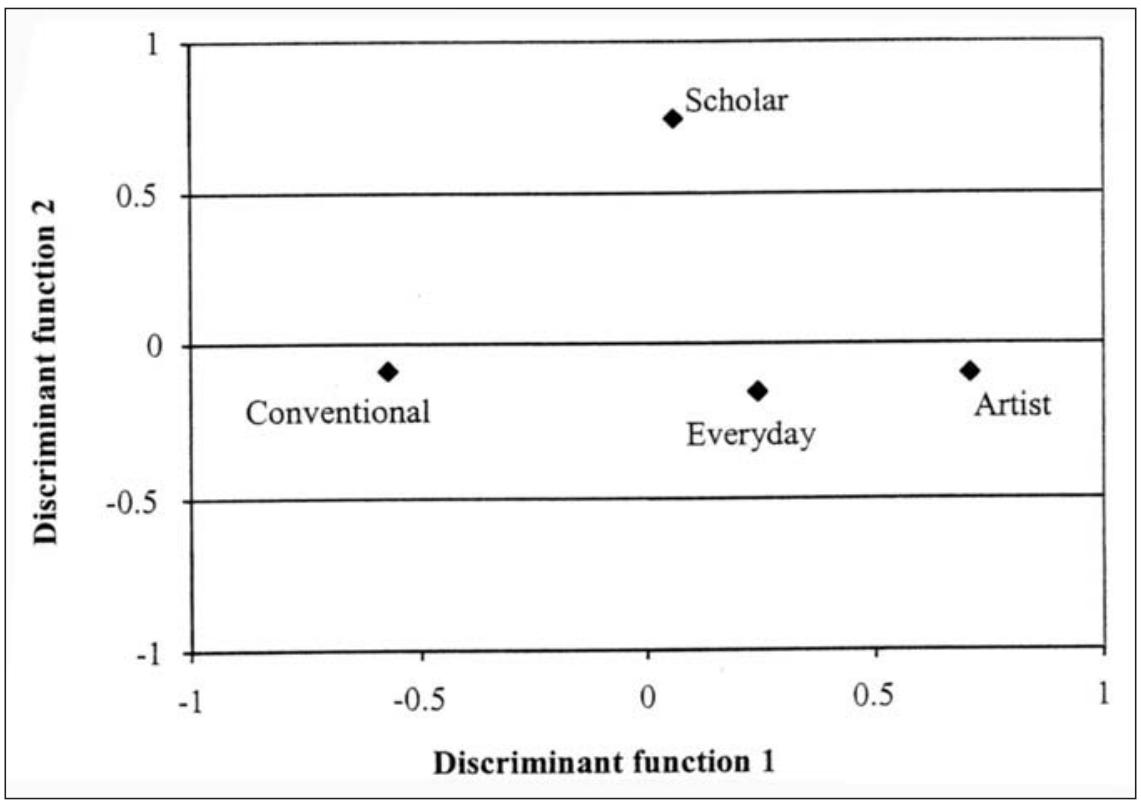

Figure 3. Group centroids on two discriminant functions based on creativity relevant personality traits. 
Creative Person and Scholar clusters falling in between them. The second discriminant function was described by intrinsic motivation, risk-taking, and divergent thinking. This group of traits separated the Scholar from the other three clusters (see Figure 3).

To test which pairs of clusters were significantly distinguished by the two discriminant functions, a series of post-hoc Tukey HSD tests was performed (see Table 2 for pair-wise comparisons). The first discriminant function significantly distinguished the Conventional Person cluster from other three clusters, showing that traits defining this function differentiate non-creativity from various kinds of creativity. That same discriminant function also significantly distinguished the Artist cluster from other clusters. This finding might reflect the variety of behaviors in the Artists (above average on both creative life-style and performing arts dimensions). The second discriminant function significantly distinguished the Scholar cluster from other three clusters.

\section{DISCUSSION}

Many scholars have called for studies examining patterns or profiles in behavior $[51,67,68]$. In the present study we identified groups of people with distinct

Table 2. Absolute Values of All Pair-Wise Contrasts among Cluster Means on Two Discriminant Functions of Personality Traits

\begin{tabular}{|c|c|c|c|c|}
\hline & 1 & 2 & 3 & 4 \\
\hline $\begin{array}{l}\text { Discriminant function one } \\
\text { 1. Conventional person } \\
M=-.57\end{array}$ & - & & & \\
\hline $\begin{array}{l}\text { 2. Everyday creative person } \\
M=.24\end{array}$ & $.81 * \star \star$ & - & & \\
\hline $\begin{array}{l}\text { 3. Artist } \\
M=.70\end{array}$ & $1.27^{\star * \star}$ & $.46^{*}$ & $-63^{\star *}$ & - \\
\hline $\begin{array}{l}\text { 4. Scholar } \\
\qquad M=.07\end{array}$ & $.64^{\star \star \star}$ & .17 & & \\
\hline Discriminant function two & & & & \\
\hline $\begin{array}{l}\text { 1. Conventional person } \\
M=-.08\end{array}$ & - & & & \\
\hline $\begin{array}{l}\text { 2. Everyday creative person } \\
\qquad M=-.16\end{array}$ & .08 & - & & \\
\hline $\begin{array}{l}\text { 3. Artist } \\
\qquad M=-.09\end{array}$ & .01 & .07 & - & \\
\hline $\begin{array}{l}\text { 4. Scholar } \\
\qquad M=.73\end{array}$ & $.82^{\star \star \star}$ & 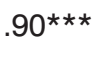 & $.82^{\star \star \star}$ & - \\
\hline
\end{tabular}

${ }^{\star} p<.05 .{ }^{* *} p<.01 .{ }^{* *} p<.001$. 
patterns of creativity and examined personality differences among thus identified creative types. Furthermore, this research measured creativity in formal domains of work, such as the arts, but it also measured creative life-style, which is a generally neglected domain of creativity [14].

Five creative types were identified, ranging from uncreative to those creative in multiple domains. The modal type showed an above average creative life-style and below average involvement in the arts and intellectual achievement pursuits (38.5\% of participants). The type with below average creativity on all three dimensions was the second largest (33.4\% of the total sample). Two types described artists and scholars (between $12.5 \%$ and $14.2 \%$ of the sample); when people get involved in artistic or activities of intellectual creativity, they are most likely to primarily pursue one kind of work, while also having a creative life-style. Finally, a small number of people are involved in multiple domains of creativity (1.4\% of the total sample). These results support the theoretical and empirical arguments that creativity is largely domain specific [69]; three out of five types showed a profile with a peak on one dimension of creativity and a very small number of people showed creativity on multiple dimensions.

Results showing both specificity and generality point to the need to better understand different kinds of creativity. Creativity is often assessed without regard to the domain of work [6]. Since most creativity appears to be rather domain specific, it is useful to assess creativity in specific domains and make conclusions limited to those domains. It also will be important for future research to identify individuals who are creative in multiple domains. In this study, the number of such renaissance people was too small to be included in statistical analyses. Much larger or more targeted samples will be needed to learn about this rather rarely studied group of creators. What are the biographical correlates of creative achievement in multiple domains? Do such creators differ in their personality traits and cognitive abilities from more narrowly specialized creators? Research by Root-Bernstein and colleagues suggests that creativity in multiple domains is most likely in very eminent creators; for example, more Nobel prize laureates showed creativity in multiple domains of work than their less eminent peers [17-19].

We were also able to learn about creative types by examining their personality traits. Because previous research showed that creativity requires multiple resources within a person, creativity-relevant predictors were selected to represent the major areas of personality and the system as a whole. One set of traits differentiated uncreative and creative people and another set of traits distinguished the scholars from other types. The first set of traits included openness to experience, trait hypomania, creative role, and intellectual curiosity and persistence. Because they differentiate creativity and non-creativity, these traits can be interpreted as creativity-general. The core description of a creative person could thus include imagination, complexity, and innovativeness (traits of openness to experience), a great amount of energy, belief in self-uniqueness, and wide interests (hypomanic traits), self-definition as artist or scholar (creative role), and 
inquisitiveness and interest in complex material (intellectual curiosity and persistence). This description of a creative person is in agreement with previously reported personality descriptions of creativity $[42,43,70]$.

The second set of traits, which could be labeled creative scholarship, included intrinsic motivation, risk-taking, and divergent thinking and accounted for differences between scholars and other types. This set of traits showed that the scholars find enjoyment and challenge in work (intrinsic motivation), are willing to take chances in the professional and financial areas (risk-taking), and are able to generate multiple ideas when presented with a problem (divergent thinking). The predictive validity of these traits of creative scholarship is less than for the set of creativity-general traits, indicating that personality traits are most successful in predicting a fundamental decision to engage in creativity and less successful in prediction of the domain-specific nature of creativity [22].

Typological analyses offered an alternative view to common descriptions of creativity. The dominant research model provides a picture of isolated dimensions of creativity and their relationship with personality traits and other psychological attributes, but it does not take into account patterns of creativity. An important advantage of a typological approach is that identification of patterns of creativity can suggest common psychological and developmental mechanisms behind the observed patterns $[71,72]$. Figure 4 illustrates one possible model that is compatible with the findings of this study, as well as previous theory and research on development of creativity. In this model, creative life-style is interpreted to be the most elementary form of creativity; it is a general attribute of everyday behavior style and it does not require specialized training. This everyday behavior style is related to curiosity and exploratory behavior and is likely to develop in children who experience supportive parenting that encourages a sense of psychological freedom and safety [73, 74]. Those that do not show such early creativity, are not likely to develop other creativity.

Those who show early everyday creativity may follow one of two courses. Some may continue to apply their creativity chiefly to everyday social relationships and activities (i.e., creative life-style). They may dress in an original way, design their own jewelry or hairstyles, create holiday cards for their family, and continually surprise their friends. In adulthood, they may use their creativity to devise new games with their children or to come up with original ideas about how to raise funds for a local homeless shelter. Generally, these manifestations of creativity can be described as expressions of resourcefulness, imagination, and inventiveness and they do not need specialized training.

Some individuals who show an early creative life-style, however, may extend this behavioral style into formal domains of creativity, such as the arts or intellectual achievement. That is, although a creative life-style may be the sole expression of creativity in some people, it may co-occur or further develop into more formal and specialized types of creativity. For example, a child who is curious and playful might become interested in understanding the natural world. The child can 


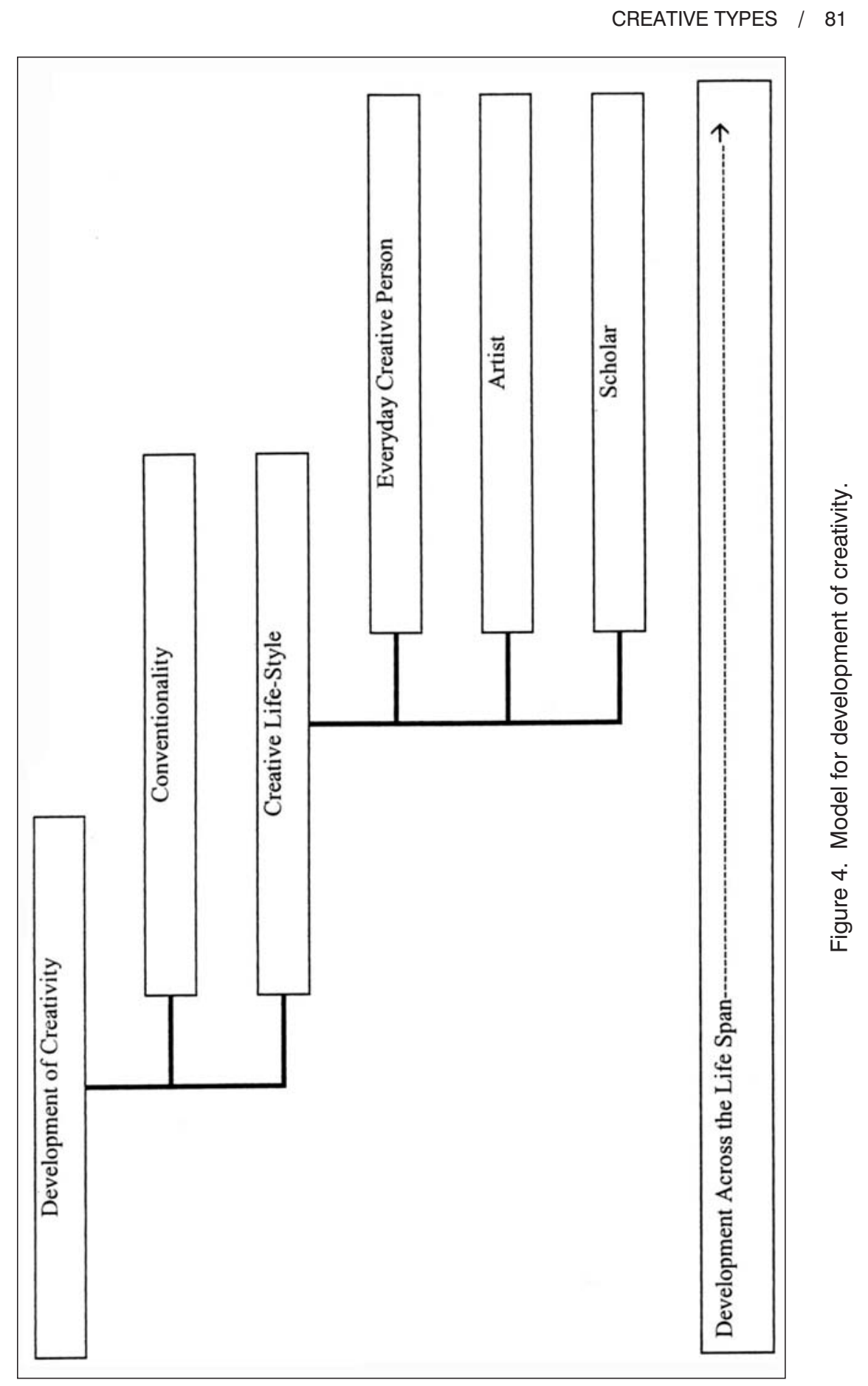


learn that science is able to answer many questions about nature. In high school or college, he or she can learn that by becoming a scientist one can continue asking questions and find new ways to answer them. In this way, childhood curiosity and playfulness can develop into a specific creative expression, in this case expressed in scholarly activity. Indeed, childhood imaginative activities similar to creative life-style (e.g., writing poems and reading) are antecedents of adult occupational creativity [42].

The developmental model proposed here is supported by theoretical and empirical work on the development of creativity. For instance, Cohen [75] defined creativity on a continuum of seven levels, from universal creativity characteristic of childhood to creativity that brings about revolutions in one or more domains of work. The developmental path from childhood creativity to mature forms of creative production is dependent on one's social and educational experiences. Similarly, Feldman [76] described creativity in children as similar to what he termed low-range creativity; children's products and ideas might be surprising and original for the particular individual, but they do not have a lasting effect on a domain of work. Forms of creativity in the middle and high range become possible in a process of skill development, acquisition of domain knowledge, and sustained effort in face of failure. The level of achievement in formal domains would depend on the availability of mentors and rewards, cultural value ascribed to different areas of creative expression, and developed interests [77].

\section{ACKNOWLEDGMENTS}

The authors gratefully acknowledge the contributions of Rebecca Warner and David Pillemer who commented on earlier drafts of the article.

\section{REFERENCES}

1. S. Freud, Creative Writers and Daydreaming, in The Standard Edition of the Complete Psychological Works of Sigmund Freud (Vol. 9), J. Strachey (ed.), Hogarth Press, London, 1959. (Original work published 1908.)

2. A. H. Maslow, The Farther Reaches of Human Nature, Penguin Books, New York, 1971.

3. H. J. Eysenck, Genius: The Natural History of Creativity, Cambridge University Press, Cambridge, United Kingdom, 1995.

4. J. P. Guilford, Creativity: A Quarter of Century of Progress, in Perspectives in Creativity, I. A. Taylor and J. W. Getzels (eds.), Aldine Publishing Company, Chicago, pp. 37-59, 1975.

5. G. J. Feist, A Meta-Analysis of Personality in Scientific and Artistic Creativity, Personality and Social Psychology Review, 2, pp. 290-309, 1998.

6. L. A. King, L. M. Walker, and S. J. Broyles, Creativity and the Five Factor Model, Journal of Research in Personality, 30, pp. 189-203, 1996.

7. R. R. McCrae, Creativity, Divergent Thinking, and Openness to Experience, Journal of Personality and Social Psychology, 52, pp. 1258-1265, 1987. 
8. H. Gardner, Frames of Mind: The Theory of Multiple Intelligences. Basic Books, New York, 1993.

9. M. A. Runco and M. D. Bahleda, Implicit Theories of Artistic, Scientific and Everyday Creativity, Journal of Creative Behavior, 20, pp. 93-98, 1986.

10. J. C. Kaufman and J. Baer, Sure, I'm Creative-But Not in Mathematics!: SelfReported Creativity in Diverse Domains, Empirical Studies of the Arts, 22, pp. 143-155, 2004.

11. F. Barron, Putting Creativity to Work, in Nature of Creativity, R. J. Sternberg (ed.), Cambridge University Press, Cambridge, MA, 1988.

12. M. Csikszentmihalyi, Creativity: Flow and the Psychology of Discovery and Invention, HarperCollins Publishers, New York, 1996.

13. R. J. Sternberg, J. C. Kaufman, and J. E. Pretz, The Creativity Conundrum: A Propulsion Model of Kinds of Creative Contributions, Psychology Press, Philadelphia, Pennsylvania, 2001.

14. R. Richards, D. K. Kinney, M. Benet, and A. P. C. Merzel, Assessing Everyday Creativity: Characteristics of the Everyday Creativity Scales and Validation with Three Large Samples, Journal of Personality and Social Psychology, 54, pp. 467-485, 1988.

15. S. J. Guastello and J. E. Shissler, A Two-Factor Taxonomy of Creative Behavior, Journal of Creative Behavior, 28, pp. 211-221, 1994.

16. Z. Ivcevic, and J. D. Mayer, Mapping Dimensions of Creative Behavior in the Life-Space, manuscript submitted for publication, 2006.

17. R. S. Root-Bernstein, The Art of Innovation: Polymaths and the Universality of the Creative Process, in International Handbook of Innovation, L. Shavanina (ed.), Elsevier, Amsterdam, The Netherlands, pp. 267-278, 2003.

18. R. S. Root-Bernstein, M. Bernstein, and H. Garnier, Correlations Between Avocations, Scientific Style, Work Habits, and Professional Impact of Scientists, Creativity Research Journal, 8, pp. 115-137, 1995.

19. R. S. Root-Bernstein and M. Root-Bernstein, Artistic Scientists and Scientific Artists: The Link Between Polymathy and Creativity, in Creativity: From Potential to Realization, R. J. Sternberg, E. L. Grigorenko, and J. L. Singer (eds.), American Psychological Association, Washington, D.C., pp. 127-151, 2004.

20. T. M. Amabile, Creativity in Context, Westview Press, Boulder, Colorado, 1996.

21. M. D. Mumford and S. B. Gustafson, Creativity Syndrome: Integration, Application, and Innovation, Psychological Bulletin, 103, pp. 24-43, 1988.

22. R. J. Sternberg and T. I. Lubart, Defying the Crowd: Cultivating Creativity in a Culture of Conformity, The Free Press, New York, 1995.

23. D. C. Funder, Personality, Annual Review of Psychology, 52, pp. 197-221, 2001.

24. J. D. Mayer, A Tale of Two Visions: Can a New View of Personality Help Integrate Psychology? American Psychologist, 80, pp. 294-307, 2005.

25. L. R. Goldberg, The Structure of Phenotypic Personality Traits, American Psychologist, 48, pp. 26-34, 1993.

26. J. D. Mayer, Structural Divisions of Personality and the Classification of Traits, Review of General Psychology, 7, pp. 381-401, 2003.

27. O. P. John and S. Srivastava, The Big Five Trait Taxonomy: History, Measurement, and Theoretical Perspectives, in Handbook of Personality, L. A. Pervin and O. P. John (eds.), Guilford Press, New York, pp. 102-138, 1999. 


\section{4 / IVCEVIC AND MAYER}

28. S. V. Paunonen, Big Five Factors of Personality and Replicated Predictions of Behavior, Journal of Personality and Social Psychology, 84, pp. 411-422, 2003.

29. M. Griffin and M. R. McDermott, Exploring a Tripartite Relationship Between Rebelliousness, Openness to Experience, and Creativity, Social Behavior and Personality, 26, pp. 347-356, 1998.

30. T. M. Amabile, K. G. Hill, B. A. Hennessey, and E. M. Tighe, The Work Preference Inventory: Assessing Intrinsic and Extrinsic Motivational Orientations, Journal of Personality and Social Psychology, 66, pp. 950-967, 1994.

31. R. Eisenberger and L. Rhoades, Incremental Effects of Reward on Creativity, Journal of Personality and Social Psychology, 81, pp. 728-741, 2001.

32. R. Eisenberger, L. Rhoades, and J. Cameron, Does Pay for Performance Increase or Decrease Perceived Self-Determination and Intrinsic Motivation? Journal of Personality and Social Psychology, 77, pp. 1026-1040, 1999.

33. M. Eckblad and L. J. Chapman, Development and Validation of a Scale for Hypomanic Personality, Journal of Abnormal Psychology, 95, pp. 214-222, 1986.

34. D. Schuldberg, Schizotypal and Hypomanic Traits, Creativity, and Psychological Health, Creativity Research Journal, 3, pp. 218-230, 1990.

35. D. Schuldberg, Creativity, Bipolarity, and the Dynamics of Style, in Affect, Creative Experience, and Psychological Adjustment, S. Russ (ed.), Brunner/Mazel, Philadelphia, Pennsylvania, pp. 221-237, 1999.

36. K. R. Jamison, Manic-Depressive Illness and Accomplishment: Creativity, Leadership, and Social Class, in Manic-Depressive Illness, F. Goodwin and K. R. Jamison (eds.), Oxford University Press, New York, pp. 332-367, 1990.

37. J. P. Guilford and R. Hoepfner, The Analysis of Intelligence, McGraw-Hill, New York, 1971.

38. E. P. Torrance, The Nature of Creativity as Manifest in its Testing, in The Nature of Creativity, R. J. Sternberg (ed.), Cambridge University Press, Cambridge, Massachusetts, pp. 43-75, 1988.

39. I. Chand and M. A. Runco, Problem Finding Skills as Components of the Creative Process, Personality and Individual Differences, 14, pp. 155-162, 1992.

40. M. A. Runco and W. R. Smith, Interpersonal and Intra-Personal Evaluations of Creative Ideas, Personality and Individual Differences, 13, pp. 295-302, 1992.

41. T. Merten and I. Fischer, Creativity, Personality and Word Association Responses: Associative Behaviour in Forty Supposedly Creative Persons, Personality and Individual Differences, 27, pp. 933-942, 1999.

42. R. Helson, B. Roberts, and G. Agronick, Enduringness and Change in Creative Personality and the Prediction of Occupational Creativity, Journal of Personality and Social Psychology, 69, pp. 1173-1183, 1995.

43. H. G. Gough, Assessment of Creative Potential in Psychology and the Development of a Creative Temperament Scale for the CPI, in Advances in Psychological Assessment, J. C. Rosen and P. McReynolds (eds.), pp. 225-257, 1992.

44. G. Domino, Identification of Potentially Creative Persons from the Adjective Check List, Journal of Consulting and Clinical Psychology, 35, pp. 48-51, 1970.

45. K. O. Gotz and K. Gotz, Personality Characteristics of Professional Artists, Perceptual and Motor Skills, 49, pp. 327-334, 1979.

46. J. P. Rushton, Creativity, Intelligence, and Psychoticism, Personality and Individual Differences, 11, pp. 1291-1298, 1990. 
47. R. S. Friedman, and J. Foerster, The Effects of Promotion and Prevention Cues on Creativity, Journal of Personality and Social Psychology, 81, pp. 1001-1013, 2001.

48. J. A. Glover and F. Sautter, Relation of Four Components of Creativity to Risk-Taking Preferences, Psychological Reports, 41, pp. 227-230, 1977.

49. T. I. Lubart and R. J. Sternberg, An Investment Approach to Creativity: Theory and Data, in The Creative Cognition Approach, S. M. Smith, T. B. Ward, and R. A. Finke (eds.), MIT Press, Cambridge, Massachusetts, pp. 269-302, 1995.

50. R. N. Wilson, The American Poet: A Role Investigation, Taylor and Francis, New York, 1990.

51. K. L. York and O. P. John, The Four Faces of Eve: A Typological Analysis of Women's Personality at Midlife, Journal of Personality and Social Psychology, 63, pp. 494-508, 1992.

52. S. J. Guastello, Artistic and Scientific Activities Survey, unpublished test, 1991.

53. D. Hocevar, The Development of the Creative Behavior Inventory, paper presented at the Annual Meeting of the Rocky Mountain Psychological Association, 1979.

54. O. P. John, E. M. Donahue, and R. L. Kentle, The Big Five Inventory-Versions $4 a$ and $4 b$. Technical Report, Institute of Personality and Social Research, University of California, Berkeley, California, 1991.

55. M. A. Wallach and N. Kogan, Modes of Thinking in Young Children. A Study of the Creativity-Intelligence Distinction, Holt, Rinehart, and Winston, New York, 1965.

56. F. Barron, Symbolic Equivalence Test, unpublished test, 1967.

57. L. J. Chapman, J. P. Chapman, J. S. Numbers, W. S. Edell, B. N. Carpenter, and D. Beckfield, Impulsive Nonconformity as a Trait Contributing to the Prediction of Psychotic-Like and Schizotypal Symptoms, Journal of Nervous and Mental Disease, 172, pp. 681-691, 1984.

58. D. Lufi and A. Cohen, A Scale for Measuring Persistence in Children, Journal of Personality Assessment, 51, pp. 178-185, 1987.

59. J. S. Tanaka, A. T. Panter, and W. C. Winborne, Dimensions of the Need for Cognition: Subscales and Gender Differences, Multivariate Behavioral Research, 23, pp. 35-50, 1988.

60. Z. Ivcevic, Creativity or Creativities: A Study of Domain Generality and Specificity, unpublished doctoral dissertation, 2005.

61. D. N. Jackson, L. Hourany, and N. Vidmar, A Four Dimensional Interpretation of Risk-Taking, Research Bulletin No. 185, University of Western Ontario, 1971.

62. M. S. Aldenderfer and R. K. Blashfield, Cluster Analysis, Sage Publications, Beverly Hills, California, 1984.

63. R. K. Blashfield, Mixture Model Tests of Cluster Analysis: Accuracy of Four Agglomerative Hierarchical Methods, Psychological Bulletin, 83, pp. 377-388, 1976.

64. R. J. Sternberg, E. Grigorenko, and J. L. Singer, J. L. (eds.), Creativity: From Potential to Realization, American Psychological Association, Washington, D.C., 2004.

65. J. B. Asendorpf, P. Borkenau, F. Ostendorf, and M. A. G. van Aken, Carving Personality Description at its Joints: Confirmation of Three Replicable Personality Prototypes for both Children and Adults, European Journal of Personality, 15, pp. 169-198, 2001.

66. A. Caspi and P. A. Silva, Temperamental Qualities at Age Three Predict Personality Traits in Young Adulthood: Longitudinal Evidence from a Birth Cohort, Child Development, 66, pp. 486-498, 1995. 
67. L. Pulkkinen, K. Männikkö, and J. E. Nurmi, Self-Description and Personality Styles, in Developmental Science and the Holistic Approach, L. R. Bergman and R. B. Cairns (eds.), Lawrence Erlbaum Associates, Mahwah, New Jersey, pp. 265-280, 2001.

68. R. W. Robins, O. P. John, and A. Caspi, Resilient, Overcontrolled, and Undercontrolled Boys: Three Replicable Personality Types, Journal of Personality and Social Psychology, 70, pp. 157-171, 1996.

69. J. C. Kaufman and J. Baer, Hawking's Haiku, Madonna's Math: Why it is Hard to be Creative in Every Room of the House, in Creativity: From Potential to Realization, R. J. Sternberg, E. L. Grigorenko, and J. L. Singer (eds.), American Psychological Association, Washington, D.C., pp. 3-19, 2004 b.

70. F. X. Barron and D. M. Harrington, Creativity, Intelligence, and Personality, Annual Review of Psychology, 32, pp. 439-476, 1981.

71. L. R. Bergman, The Application of a Person-Centered Approach: Types and Clusters, in Developmental Science and the Holistic Approach, L. R. Bergman and R. B. Cairns (eds.), Lawrence Erlbaum Associates, Mahwah, New Jersey, pp. 137-154, 2000.

72. S. Gangestad and M. Snyder, "To Carve Nature at its Joints": On the Existence of Discrete Classes in Personality, Psychological Review, 92, pp. 317-349, 1985.

73. D. M. Harrington, J. H. Block, and J. Block, Testing Aspects of Carl Rogers' Theory of Creative Environments: Child-Rearing Antecedents of Creative Potential in Young Adolescents, Journal of Personality and Social Psychology, 52, pp. 851-856, 1987.

74. C. R. Rogers, Towards a Theory of Creativity, ETC: A Review of General Semantics, 11, pp. 249-260, 1954.

75. L. M. Cohen, A Continuum of Adaptive Creative Behaviors, Creativity Research Journal, 2, pp. 169-183, 1989.

76. D. H. Feldman, Key Issues in Creativity and Development, in Creativity and Development, R. K. Sawyer, V. John-Steiner, S. Moran, R. J. Sternberg, D. H. Feldman, J. Nakamura and M. Csikszentmihalyi (eds.), Oxford University Press, New York, pp. 217-242, 2003.

77. M. Csikszentmihalyi, Implications of a Systems Perspective for the Study of Creativity, in Handbook of Creativity, R. J. Sternberg (ed.), Cambridge University Press, New York, pp. 313-338, 1999.

Direct reprint requests to:

Zorana Ivcevic

Department of Psychology

University of New Hampshire

Conant Hall

10 Library Way

Durham, NH 03824

e-mail: zivcevic@unh.edu 